\title{
Burden of tuberculosis disease among adolescents in a rural cohort in Eastern Uganda
}

James Waako ${ }^{1,3^{*}}$, Suzanne Verver ${ }^{2}$, Anne Wajja ${ }^{1,3}$, Willy Ssengooba ${ }^{4,3}$, Moses L Joloba ${ }^{4}$, Robert Colebunders ${ }^{5,6}$, Philippa Musoke ${ }^{3,7}$ and Harriet Mayanja-Kizza, ${ }^{3,8}$

\begin{abstract}
Background: The world health organization (WHO) declared tuberculosis (TB) a global emergency, mainly affecting people in sub-Saharan Africa. However there is little data about the burden of TB among adolescents. We estimated the prevalence and incidence of TB and assessed factors associated with TB among adolescents aged 12-18 years in a rural population in Uganda in order to prepare the site for phase III clinical trials with novel TB vaccines among adolescents.

Methods: In a prospective cohort study, we recruited 5000 adolescents and followed them actively, every 6 months, for 1-2 years. Participants suspected of having TB were those who had any of; TB signs and symptoms, history of TB contact or a positive tuberculin skin test (TST) of $\geq 10 \mathrm{~mm}$. Laboratory investigations included sputum smear microscopy and culture.

Results: Of the 5000 participants, eight culture confirmed cases of TB were found at baseline: a prevalence of 160/100,000 (95\% confidence interval (Cl), 69-315). There were 13 incident TB cases detected in an average of 1.1 person years: an incidence of $235 / 100,000$ person years ( $95 \% \mathrm{Cl}, 125-402)$. None of the confirmed TB cases were HIV infected. Predictors for prevalent TB disease were: a history of TB contact and a cough $\geq 2$ weeks at baseline and being out of school, while the only predictor for incident TB was a positive TST during follow-up.

Conclusion: The TB incidence among adolescents in this rural part of Uganda seemed too low for a phase III TB vaccine trial. However, the study site demonstrated capability to handle a large number of participants with minimal loss to follow-up and its suitability for future clinical trials. Improved contact tracing in TB program activities is likely to increase TB case detection among adolescents. Future studies should explore possible pockets of higher TB incidence in urban areas and among out of school youth.
\end{abstract}

\section{Background}

Tuberculosis (TB) is a global emergency causing high morbidity and mortality especially in sub-Saharan Africa [1]. The immune response against Mycobacterium tuberculosis (MTB) is less effective among adolescents [2]. Adolescents have peculiar clinical TB manifestations and may present without symptoms but are more likely to have cavitating disease compared to adults or children [3]. Vaccination against TB using Bacillus Calmette-Guerin (BCG) in neonates has led to a reduction in incidence of

\footnotetext{
* Correspondence: waakojames@yahoo.com

${ }^{1}$ Makerere University Iganga/Mayuge Demographic Surveillance Site, P.O BOX. 22418, Kampala, Uganda

${ }^{3}$ Makerere University Infectious Diseases Institute, Kampala, Uganda

Full list of author information is available at the end of the article
}

severe childhood TB and deaths including miliary TB and TB meningitis [4]. Despite BCG immunization, adult forms of TB continue to emerge implying the current vaccine has limited efficacy against adult TB and therefore a need for new $\mathrm{TB}$ vaccines with high protective efficacy [5-7]. The risk of developing TB following infection starts to rise from 12-19 years making it a suitable age group for new TB vaccines [8].

Diagnosed TB among adolescents in most countries is aggregated and reported together with adult TB cases, disaggregated as $0-14$ and $15-25$ years, with limited information specific to adolescents. Very few studies have investigated $\mathrm{TB}$ prevalence and incidence of $\mathrm{TB}$ among adolescents [9]. Uganda is ranked 16th among the $22 \mathrm{~TB}$ high burden countries globally, with estimated incidence

\section{Biomed Central}


rates of about 209 per 100,000 population per year for all forms of TB in 2010 [10]. The estimated prevalence was $193 / 100,000$ population for all forms of TB in 2010. However, the country notified an incidence of $128 / 100,000$ population, only $66 \%$ of the estimated incidence [1].

The objectives of the study were to estimate the prevalence and incidence of $\mathrm{TB}$ and assess factors associated with TB among adolescents aged 12-18 years in a rural population in Uganda in order to prepare the site for phase III clinical trials with novel TB vaccines among adolescents.

\section{Methods}

The study was conducted in the Makerere University School of Public Health Demographic Surveillance Site (DSS) in Iganga and Mayuge districts, located $120 \mathrm{~km}$ east of Kampala between September 2009 and September 2011. The study area is $80 \%$ rural and $20 \%$ peri-urban with nine health facilities offering free TB smear microscopy and treatment. The study area had a population of approximately 12,000 adolescents aged $12-18$ years.

Participants aged 12-18 years who were resident in the study area for the previous three months were approached both in school and at home. Those who gave written assent after the parents/legal guardian had provided written informed consent were enrolled into the study. Participants who were planning to move away from the study area within one year were excluded.

Adolescents were stratified into $12-14$ years, $15-16$ years and 17-18 year age groups and conveniently sampled from schools and in the community with the sample size in each age stratum proportional to the size of the stratum population in the DSS. They were recruited consecutively until the sample size of 5000 was attained. Recruitment was mainly from rural areas and all had an equal chance of inclusion in the study. Given the World Health Organization (WHO) estimated incidence for 2007 of $330 / 100,000$ population at time of study start (September 2009) [10] and 10-20\% loss to follow-up; we expected to find among 5000 adolescents a cumulative TB incidence of $28(0.56 \%)$ cases in two years, with a 95\% CI of $\{26$ $(0.37 \%)-51(0.73 \%)\}$. These estimates were amended by WHO downwards in the later reports.

At enrolment, socio-demographic variables, relevant medical history including symptoms and signs suggestive of TB were collected. The participant's weight and temperature were taken and a physical examination done. All participants had a tuberculin skin test (TST) 2 Tuberculin Units (Danish type from Staten's Serum Institute) placed and read after 48-72 hours. Those with a negative result had a repeat TST done at one and two years of follow up. Participants were followed up every 6 months for 1-2 years and targeted history and physical examination were done. The study closed early and therefore those recruited later had a shorter duration of follow- up. Active TB suspicion was defined as participants found with any one of the following; TST induration of $\geq 10 \mathrm{~mm}$, or at least one TB related symptom: cough $\geq 2$ weeks, weight loss for $\geq 2$ weeks, fever for $\geq 2$ weeks, haemoptysis) or a history of TB contact since the last study follow up visit. Two sputum samples, a spot sample on day one and an early morning sample on day 2 were collected from all TB suspects and transported in cold boxes (temperature $\leq 8^{\circ} \mathrm{C}$ ) to the reference laboratory within 24 hours. All collected data were entered onto a pre-coded case report form (CRF).

\section{Laboratory analysis}

Sputum samples were processed in the Makerere University mycobacteriology Biosafety Level III laboratory in Kampala. All sputum samples were subjected to fluorescence microscopy and culture after concentration using $1 \%$ sodium hydroxide $(\mathrm{NAOH}) / \mathrm{N}$-acetyl L-cysteine (NALC) and sodium citrate method [11]. Cultures were performed by both solid (Lowenstein-Jensen, (Becton and Dickson, Franklin Lakes, NJ USA)) and liquid Mycobacterium Growth Indicator Tube (MGIT) culture techniques and incubated for six to eight weeks. Species identification was done using Capilia TB $\mathrm{Neo}^{\mathrm{Tm}}$ (TAUN, Numazu, Japan) assay for all ZiehlNeelsen (ZN) positive cultures to exclude mycobacteria other than tuberculosis (MOTT) and all isolates of mycobacterium tuberculosis complex (MTBC) were subjected to Hain Genotype MTBC assay for speciation. Participants with at least two positive smears or at least one MTBC culture were defined as confirmed TB cases.

\section{Ethical approval}

Ethical approval was obtained from the Makerere University School of Public Health Higher Degrees Research and Ethics Committee, the Uganda National Council for Science and Technology and the Institutional Review Board of Institute of Tropical Medicine (ITM) Antwerp of Belgium.

\section{Data analysis}

Analysis was done using STATA statistical software (Release 11.0, Stata Corporation, College Station, Texas, United States of America). Primary analysis was done by calculating frequencies for key demographic variables and overall prevalence and incidence rates; with secondary analyses done to estimate stratum specific prevalence and incidence rates by age group, sex, education, schooling status, TST outcome, TB contact and cough. Person years were calculated by subtracting the day of entry into the study from the last day of contact with the participant divided by 365 days. For those diagnosed with TB, date of diagnosis was taken as date of last contact. For those who died, date of death was taken as last date of contact. 95\% confidence intervals $(\mathrm{CI})$ were calculated using Poisson distribution. Odds ratios (OR) were calculated as a 
measure of TB risk and hazard ratios were calculated for incident TB cases. In multivariate analysis we included variables that were significant in univariate analysis at the $\mathrm{P}<0.01$ level.

\section{Results}

Among the DSS adolescents; 8000 were approached and $5422(68 \%)$ parents agreed to have their children participate in the study and 5042 (63\%) adolescents provided assent. Among the screened participants, 858 (10.7\%) were ineligible to participate mainly because they were planning to move away from the study area within one year. A total of 5000 adolescents were consecutively enrolled over a 12 month period. Of these, 1069(21.4\%) were TB suspects at baseline and 1086 (21.7\%) during follow-up. The most common reasons were, a positive TST 1307 (54.7\%), symptoms suggestive of TB 735 (30.8\%) and a history of TB contact 441 (18.5\%), Figure 1.

\section{Description of study participants}

Study participants were more often male (52\%); unmarried (99\%), aged $12-14$ years $(47 \%)$, Basoga $(82 \%)$ the predominant tribe in the area and majority were in school (94\%), Table 1. A total of 12,124 follow up visits were planned of which 10,769 (89\%) were conducted. The follow up period was at least 12 months and maximum 24 months with an overall loss to follow up of $10.5 \%$ and total person years of follow up was 5527 with mean follow up time of 1.1 person years (SD 0.3). Four participants died of: juvenile diabetes, tetanus, sickle cell anemia and a possible cardiac problem and none was due to TB. A total of $143 / 5000$ (3\%) participants were never seen again after enrollment.

\section{TB prevalence and incidence}

A total of nine TB cases out of 5000 adolescents were detected at baseline of which eight cases were confirmed microbiologically, Table 2. Of these eight, seven were

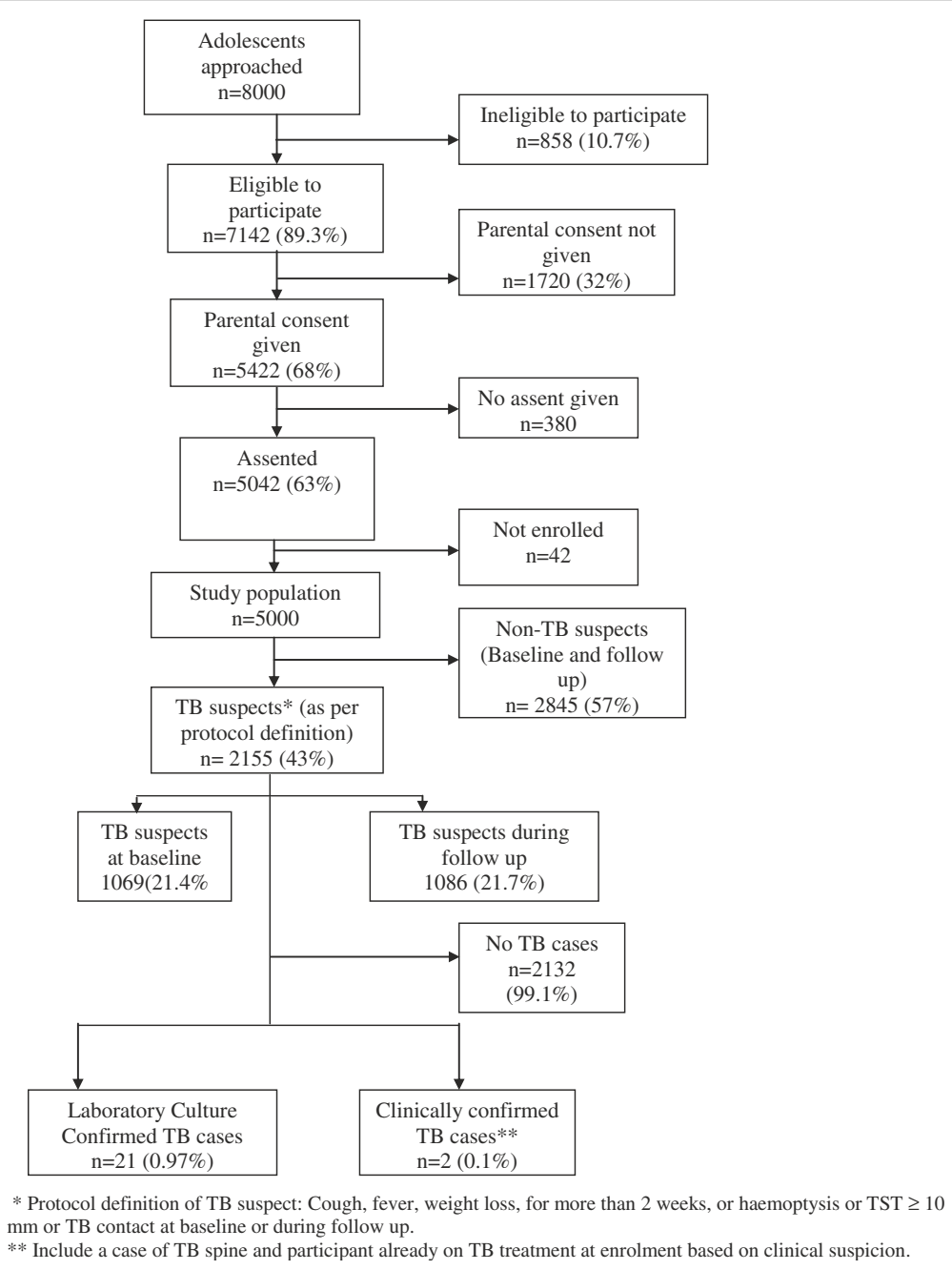

Figure 1 Study profile and TB cases among adolescents in a rural cohort in eastern Uganda. 
Table 1 Baseline characteristics of adolescents enrolled in the Iganga/Mayuge TB Cohort Study, 2009

\begin{tabular}{lll}
\hline Characteristic & Study population & Percentage \\
\hline Total & $\mathbf{5 0 0 0}$ & $\mathbf{1 0 0}$ \\
\hline Age (Years) & & \\
\hline $12-14$ & 2339 & 47 \\
\hline $15-16$ & 1482 & 29 \\
\hline $17-18$ & 1179 & 24 \\
\hline Sex & & 52 \\
\hline Male & 2589 & \\
\hline Marital status & & 0.7 \\
\hline Married & 33 & 13.9 \\
\hline Level of education & & 85 \\
\hline$>7$ years & 696 & 0.3 \\
\hline$\leq 7$ years & 4250 & 0.8 \\
\hline Never attended school & 14 & 94 \\
\hline Unknown & 40 & 18.2 \\
\hline Enrolment status & & \\
\hline In school & 4678 & 91.8 \\
\hline Out of school & 322 & \\
\hline Tribe & 4089 & \\
\hline Basoga & 911 & \\
\hline Others & & \\
\hline
\end{tabular}

smear (at least 1) and culture positive, and one was smear negative but culture positive. One of the TB cases was identified while on TB treatment (smear and culture positive). This resulted in a crude prevalence of culture confirmed TB of 160/100,000 (95\% CI, 69-315). Of these eight cases, four had only TB symptoms, three had only a history of TB contact and one had both symptoms and a TB contact. One participant was clinically diagnosed with TB in the health facility. This participant was HIV infected, had TB symptoms and history of TB contact, but sputum samples were negative on smear microscopy and culture, Table 2. There were no prevalent TB cases among adolescents with a negative TST.

During follow up, 14 cases of TB were detected of which 13 were culture confirmed (all smear negative) and one was clinically diagnosed with TB. The average duration of follow up was 1.1 years. The incidence of bacteriologically confirmed TB was 235/100,000 person years (95\% CI, 125-402). All TB cases were HIV negative. Nine (64\%) reported no symptoms and none had CXR abnormalities (CXR was done for only nine cases after start of treatment for clinical care purposes), Table 3.

\section{Predictors for prevalent TB}

At baseline there was no significant difference in adolescents with bacteriologically confirmed TB by sex, age groups, and levels of education. Participants who were out of school were seven times more likely to have TB than their in-school counter parts (AOR 6.84; 01.2836.03). Participants who had contact with a TB patient were sixteen times more likely to have TB compared to those with no TB contact (AOR 15.67; 3.57 -68.77). Those who had had cough for $\geq 14$ days were five times more likely to have TB than those who had had cough for $\leq 14$ days or no cough at all (AOR 5.15; 1.20-22.10), Tables 4 and 5 .

\section{Predictors for incident TB}

On multivariate analysis, bacteriologically confirmed TB incidence during follow up was significantly higher among participants with a positive TST $\geq 10 \mathrm{~mm}$ than their TST negative counter parts ( adjusted hazard ratio 58.08; 95\% CI 7.2-435). The incidence of TB seemed to increase with age though this trend was not significant, $\mathrm{p}$-value $=0.093$. Incidence was similar among those with $\geq$ seven years of schooling compared to those with lower education level (Adjusted hazard ratio 0.9; 0.20,

Table 2 Clinical and laboratory characteristics of prevalent TB cases $(n=9)$

\begin{tabular}{|c|c|c|c|c|c|c|c|}
\hline Case number & TB symptoms & TB contact & $\mathrm{TST} \geq 10 \mathrm{~mm}$ & $\begin{array}{l}\text { CXR abnormalities } \\
\text { present }\end{array}$ & $\begin{array}{l}\text { Smear } \\
\text { positive }\end{array}$ & $\begin{array}{l}\text { Culture } \\
\text { positive }\end{array}$ & $\begin{array}{l}\text { Case determination } \\
\text { criteria }\end{array}$ \\
\hline 1. & No & Yes & Yes & Yes & Yes & Yes & Smear and culture \\
\hline 2. & Yes & No & Yes & No & Yes & Yes & Smear and culture \\
\hline 3. & Yes & No & Yes & Yes & Yes & Yes & Smear and culture \\
\hline 4. & Yes & No & Yes & Yes & Yes & Yes & Smear and culture \\
\hline 5. & No & Yes & Yes & No & Yes & Yes & Smear and culture \\
\hline 6. & No & Yes & Yes & Yes & Yes & Yes & Smear and culture \\
\hline 7. & Yes & No & Yes & No & Yes & Yes & Culture only \\
\hline 8. & Yes & Yes & Yes & Yes & Yes & Yes & Smear and culture \\
\hline 9. $\quad * * *$ & Yes & Yes & Yes & Yes & No & No & Clinical diagnosis \\
\hline Total & 6 & 5 & 9 & 6 & 8 & 8 & \\
\hline
\end{tabular}

*** HIV positive participant.

Abbreviation: Key: TB Tuberculosis, TST Tuberculin Skin Test, CXR Chest X-Ray. 
Table 3 Clinical and laboratory characteristics of the adolescent incident TB cases $(\mathbf{n}=14)$

\begin{tabular}{|c|c|c|c|c|c|c|c|c|}
\hline Case number & $\begin{array}{l}\text { Visit detected } \\
\text { (months) }\end{array}$ & TB symptoms & TB contact & $\mathrm{TST} \geq 10 \mathrm{~mm}$ & $\begin{array}{l}\text { CXR } \\
\text { abnormalities }\end{array}$ & $\begin{array}{l}\text { Smear } \\
\text { positive }\end{array}$ & $\begin{array}{l}\text { Culture } \\
\text { positive }\end{array}$ & $\begin{array}{l}\text { Case determination } \\
\text { criteria }^{1}\end{array}$ \\
\hline 1 & 12 & Yes & No & Yes & Not done & No & Yes & Culture \\
\hline 2 & 6 & Yes & No & Yes & Yes** & No & No & Clinical diagnosis $\boldsymbol{\Lambda}$ \\
\hline 3 & 12 & No & No & Yes & No & No & Yes & Culture \\
\hline 4 & 12 & No & No & Yes & No & No & Yes & Culture \\
\hline 5 & 12 & No & Yes & Yes & No & No & Yes & Culture \\
\hline 6 & 12 & No & Yes & Yes & No & No & Yes & Culture \\
\hline 7 & 12 & No & No & Yes & No & No & Yes & Culture \\
\hline 8 & 12 & No & No & Yes & Not done & No & Yes & Culture \\
\hline 9 & 12 & No & No & Yes & Not done & No & Yes & Culture \\
\hline 10 & 12 & Yes & No & Yes & Not done & No & Yes & Culture \\
\hline 11 & 24 & No & No & Yes & No & No & Yes & Culture \\
\hline 12 & 24 & No & No & Yes & No & No & Yes & Culture \\
\hline 13 & 12 & Yes & No & Yes & No & No & Yes & Culture \\
\hline 14 & 12 & Yes & No & Yes & Not done & No & Yes & Culture \\
\hline Total & & 5 & 2 & 14 & None & None & 13 & 14 \\
\hline
\end{tabular}

$\Delta$ POTTS disease.

${ }^{1}$ Culture - all smears were negative.

** Necrosis and collapse of thoracic vertebrae 10-12.

Abbreviation: Key: TB Tuberculosis, TST Tuberculin Skin Test, CXR Chest X-Ray.

Table 4 Univariate predictors of prevalent TB

\begin{tabular}{|c|c|c|c|c|}
\hline $\begin{array}{l}\text { Background } \\
\text { characteristic }\end{array}$ & $\begin{array}{l}\text { TB cases } \\
\mathbf{n}=\mathbf{8}\end{array}$ & $\begin{array}{l}\text { Population } \\
\mathrm{N}=5000\end{array}$ & $\begin{array}{l}\text { Prevalence/ } \\
100,000\end{array}$ & $\begin{array}{l}\text { P-value } \\
\text { (Chi-square test) }\end{array}$ \\
\hline \multicolumn{5}{|l|}{ Gender } \\
\hline Male & 3 & 2589 & 116 & 0.419 \\
\hline Female & 5 & 2411 & 207 & \\
\hline \multicolumn{5}{|l|}{ Age (yrs) } \\
\hline $12-14$ & 4 & 2339 & 171 & \\
\hline $15-16$ & 3 & 1482 & 202 & 0.74 \\
\hline $17-18$ & 1 & 1179 & 85 & \\
\hline \multicolumn{5}{|l|}{ Schooling status } \\
\hline Out of school & 2 & 322 & 621 & 0.032 \\
\hline In school & 6 & 4678 & 128 & \\
\hline \multicolumn{5}{|l|}{ Level of education } \\
\hline$>7$ years & 1 & 696 & 144 & \\
\hline$\leq 7$ years & 7 & 4264 & 164 & 0.961 \\
\hline Unknown & 0 & 40 & 0 & \\
\hline \multicolumn{5}{|l|}{ Baseline TST } \\
\hline Positive ( $\geq 10 \mathrm{~mm}$ ) & 8 & 802 & 998 & \\
\hline Negative $(<10 \mathrm{~mm})$ & 0 & 4179 & 0 & $<0.001$ \\
\hline Not done / Not Read & 0 & 19 & 0 & \\
\hline \multicolumn{5}{|l|}{ TB contact } \\
\hline Yes & 4 & 237 & 1409 & 0.115 \\
\hline No & 4 & 4763 & 76 & \\
\hline \multicolumn{5}{|l|}{ Cough duration (ever) } \\
\hline Cough $<14$ days & 3 & 2548 & 118 & \\
\hline No cough & 0 & 1827 & 0 & $<0.001$ \\
\hline Cough $\geq 14$ days & 5 & 625 & 800 & \\
\hline
\end{tabular}

Abbreviation: Key: TST Tuberculin Skin test.
4.06). Sex specific incidence rates showed males being three times more likely to develop $\mathrm{TB}$ than females though this difference was also not statistically significant (Adjusted hazard ratio 0.32: 0.09-1.17). TB incidence was higher among those who had TB contact and

Table 5 Associations between patient characteristics and prevalence of TB

\begin{tabular}{|c|c|c|c|c|}
\hline Background characteristic & $\begin{array}{l}\text { Unadjusted } \\
\text { OR }\end{array}$ & $95 \% \mathrm{Cl}$ & $\begin{array}{l}\text { Adjusted } \\
\text { OR }\end{array}$ & $95 \% \mathrm{Cl}$ \\
\hline \multicolumn{5}{|l|}{ Gender } \\
\hline Male & Reference & & Reference & \\
\hline Female & 1.79 & $0.43-7.50$ & 1.74 & $0.42-7.30$ \\
\hline \multicolumn{5}{|l|}{ Age (yrs) } \\
\hline $12-14$ & Reference & & Reference & \\
\hline $15-16$ & 1.18 & $0.27-5.30$ & 0.95 & $0.12-7.47$ \\
\hline $17-18$ & 0.5 & $0.06-4.34$ & 0.27 & $0.02-3.72$ \\
\hline \multicolumn{5}{|l|}{ Schooling status } \\
\hline Out of school & 4.87 & $0.98-24.21$ & 6.8 & $1.28-36.03$ \\
\hline In school & Reference & & Reference & \\
\hline \multicolumn{5}{|l|}{ Level of education } \\
\hline$>7$ years & Reference & & Reference & \\
\hline$\leq 7$ years & 1.14 & $0.14-9.30$ & 0.63 & $0.03-13.23$ \\
\hline Unknown & - & & - & \\
\hline \multicolumn{5}{|l|}{ TB contact (baseline) } \\
\hline Yes & 20.42 & $5.08-82.18$ & 15.67 & $3.57-68.77$ \\
\hline No & Reference & & Reference & \\
\hline \multicolumn{5}{|l|}{ Cough duration (ever) } \\
\hline Cough $<14$ days & Reference & & Reference & \\
\hline No cough & - & & - & \\
\hline Cough $\geq 14$ days & 6.84 & $1.63-28.70$ & 5.15 & $1.20-22.10$ \\
\hline
\end{tabular}

Abbreviation: Key: 95\% Cl 95\% Confidence Interval. 
those who had coughed for $\geq 14$ days, but this was not significant. Those with incident TB had no prior diagnosis of TB and were all school-going participants, Tables 6 and 7.

\section{Discussion}

Among adolescents 12-18 years of age in a rural setting in Uganda, we found a prevalence of TB of 160/100,000 and incidence of 235/100,000 person years. The risk factors for prevalent TB were TB contact, cough of more than 14 days and being out of school whereas for incident TB; the only risk factor was a positive TST $\geq 10 \mathrm{~mm}$.

Table 6 Univariate predictors of incident TB

\begin{tabular}{|c|c|c|c|c|c|}
\hline Determinant & Persons & Pyrs & Cases & $\begin{array}{l}\text { Incidence } \\
\text { (per 100,000 } \\
\text { pyrs) }\end{array}$ & $\begin{array}{l}\text { P-value } \\
\text { (chi-square } \\
\text { test) }\end{array}$ \\
\hline Total & 5000 & 5527 & 13 & 235 & - \\
\hline \multicolumn{6}{|c|}{$\begin{array}{l}\text { Follow up TST outcome } \\
*\end{array}$} \\
\hline Negative $<10 \mathrm{~mm}$ & 2912 & 3323 & 1 & 30 & \\
\hline Positive $\geq 10 \mathrm{~mm}$ & 582 & 679 & 11 & 1620 & $<0.001$ \\
\hline Not done/not read** & 1506 & 1525 & 1 & 66 & \\
\hline \multicolumn{6}{|l|}{ Baseline TST outcome } \\
\hline Negative < 10 mm & 4179 & 4574 & 12 & 262 & $<0.001$ \\
\hline Positive $\geq 10 \mathrm{~mm}$ & 802 & 890 & 1 & 112 & \\
\hline \multicolumn{6}{|l|}{ Prior diagnosis TB } \\
\hline No & 4990 & 5517 & 13 & 236 & - \\
\hline Yes & 10 & 11 & 0 & 0 & \\
\hline \multicolumn{6}{|l|}{ Schooling status } \\
\hline In school & 4678 & 5193 & 13 & 250 & - \\
\hline Out of school & 322 & 335 & 0 & 0 & \\
\hline \multicolumn{6}{|l|}{ Age group (years) } \\
\hline $12-14$ & 2339 & 2778 & 4 & 144 & \\
\hline $15-16$ & 1482 & 1583 & 4 & 253 & 0.093 \\
\hline $17-18$ & 1179 & 1167 & 5 & 429 & \\
\hline \multicolumn{6}{|l|}{ Sex } \\
\hline Male & 2589 & 2898 & 10 & 345 & \\
\hline Female & 2411 & 2630 & 3 & 114 & 0.028 \\
\hline \multicolumn{6}{|l|}{ Education level } \\
\hline$>7$ years & 696 & 733 & 2 & 273 & \\
\hline None & 40 & 37 & 0 & 0 & 0.752 \\
\hline$\leq 7$ years & 4264 & 4757 & 11 & 231 & \\
\hline
\end{tabular}

\section{TB Contact during}

follow-up

\begin{tabular}{llllll}
\hline No & 4732 & 5196 & 11 & 212 & 0.019 \\
\hline Yes & 268 & 331 & 2 & 604 & \\
\hline Cough during follow-up & & & & & \\
\hline$<14$ days & 2250 & 2602 & 5 & 192 & \\
\hline None & 2102 & 2307 & 6 & 260 & 0.917 \\
\hline$\geq 14$ days & 500 & 581 & 2 & 344 &
\end{tabular}

Abbreviation: Key: Pyrs Person years, TST Tuberculin Skin Test.

Note:

* One individual with TB during follow up had a positive TST of $\geq 10 \mathrm{~mm}$ at baseline;

**Those with a positive TST at baseline were not given TST again at 1 year and 2 years of follow up.
Table 7 Associations between patient characteristics and incidence of TB

\begin{tabular}{|c|c|c|c|c|}
\hline Determinant & $\begin{array}{l}\text { Unadjusted } \\
\text { hazard } \\
\text { ratio }\end{array}$ & $95 \% \mathrm{Cl}$ & $\begin{array}{l}\text { Adjusted } \\
\text { hazard } \\
\text { ratio }\end{array}$ & $95 \% \mathrm{Cl}$ \\
\hline \multicolumn{5}{|c|}{ Follow up TST outcome * } \\
\hline Negative $<10 \mathrm{~mm}$ & Reference & & Reference & \\
\hline Positive $\geq 10 \mathrm{~mm}$ & 61.28 & $7.95-472.38$ & 58.08 & $7.23-435.21$ \\
\hline \multicolumn{5}{|c|}{ Baseline TST outcome } \\
\hline Negative $<10 \mathrm{~mm}$ & Reference & & Reference & \\
\hline Positive $\geq 10 \mathrm{~mm}^{* *}$ & 1.30 & $0.37-4.63$ & 4.70 & $0.56-39.41$ \\
\hline \multicolumn{5}{|l|}{ Age group (years) } \\
\hline $12-14$ & Reference & & Reference & \\
\hline $15-16$ & 1.58 & $0.39-6.33$ & 1.58 & $0.39-6.33$ \\
\hline $17-18$ & 3.49 & $1.02-11.94$ & 2.49 & $0.67-9.28$ \\
\hline \multicolumn{5}{|l|}{ Sex } \\
\hline Male & Reference & & Reference & \\
\hline Female & 0.27 & $0.08-0.95$ & 0.32 & $0.09-1.17$ \\
\hline \multicolumn{5}{|l|}{ Education level } \\
\hline$>7$ years & Reference & & Reference & \\
\hline \multicolumn{5}{|l|}{ None } \\
\hline$\leq 7$ years & 0.65 & $0.18-2.32$ & 0.9 & $0.20-4.06$ \\
\hline \multicolumn{5}{|l|}{$\begin{array}{l}\text { TB contact during } \\
\text { follow-up }\end{array}$} \\
\hline No & Reference & & & \\
\hline Yes & 2.73 & $0.61-12.16$ & & \\
\hline \multicolumn{5}{|c|}{ Cough during follow-up } \\
\hline$<14$ days & Reference & & & \\
\hline None & 0.71 & $0.14-3.54$ & & \\
\hline$\geq 14$ days & 0.78 & $0.16-3.75$ & & \\
\hline
\end{tabular}

Key: $95 \% \mathrm{Cl}=95 \%$ Confidence Interval.

Note:

* One individual with TB during follow up had a positive TST of $\geq 10 \mathrm{~mm}$ at baseline;

${ }^{* *}$ Those with a positive TST at baseline were not given TST again at 1 year and 2 years of follow up.

All incident cases were detected at the scheduled 6 monthly visits and none through the health care system. This is probably due to active case finding leading to early detection of cases before they developed symptoms and presented to the health facilities [3]. All incident cases were culture positive but smear negative. This could have been due to sub-clinical colonization with mycobacteria. Although confidence intervals were wide, the TB prevalence of 160/100,000 in our sample was slightly lower than the estimated TB prevalence for all ages in Uganda $(193 / 100,000)$. On the other hand the TB incidence of 235/100,000 person years was slightly higher than estimated incidence for all ages in Uganda $(209 / 100,000)$ [1]. The observed differences in rates may be due to low HIV prevalence in this rural population, active TB case finding and adolescents having a lower TB incidence than the general population [1]. 
Furthermore, our study sample was mainly from a rural population, prevalence and incidence may have been much higher if an urban/peri-urban population was sampled. One of the few studies on TB prevalence in Uganda done in a slum area in Kampala city among chronic coughers $\geq 15$ years reported a TB prevalence of 4,500 / 100,000 [12]. Future studies should target adolescents in crowded settlements in urban centers. Studies done in adult populations with high HIV prevalence in Africa have reported higher TB prevalence than our study [13-17].

We did not use CXR to screen TB suspects therefore we may have underestimated the TB prevalence and incidence in our population. In our study 4265 (85.3\%) of the participants had no TB symptoms. Other prevalence surveys in the general population (usually among those aged over 15 years), that used CXR and/or symptoms to screen for TB have shown that 3852 (23\%) of participants in Western Kenya [13] and 2972 (3.4\%) in Vietnam [18] had CXR abnormalities suggestive of TB.

Risk factors for TB have been shown previously by others $[9,13-15,17]$. In our study, risk factors differed slightly between prevalent and incident cases. The high prevalence of $\mathrm{TB}$ among adolescents with $\mathrm{TB}$ contacts highlights the importance of contact tracing for increased TB case detection mainly in rural areas.

The strength of our study is the relatively large sample size and the fairly low loss to follow up rate (10.5\%). This high cohort retention is good for potential future vaccine trials. A weakness of our study however was a relatively short follow up duration of 1.1 years. It is likely that a longer follow up would have yielded more TB cases. Furthermore we did not use chest X-ray as a screening tool. This may have resulted in underestimation of prevalent TB cases as previous studies documented an increase in number of $\mathrm{TB}$ cases when chest $\mathrm{X}$-ray results were considered [19-24].

The baseline prevalence may have 'cleared' some incident cases, leading to an underestimation of the incidence. Moreover, we documented a high refusal rate from parents and adolescents. As we did not document possible reasons for refusal, we recommend future studies to explore this.

\section{Conclusion}

The TB incidence among adolescents in this rural part of Uganda seemed too low for a phase III TB vaccine trial. A positive tuberculin test $\geq 10 \mathrm{~mm}$, a history of TB contact and a cough $\geq 14$ days are the major predictors for TB disease. However, the study demonstrated the capability of the study site to handle a large number of participants with minimal loss to follow-up which is important for future clinical trials. Improved contact tracing in TB program activities is likely to increase $\mathrm{TB}$ case detection among adolescents. Future studies should explore possible pockets of higher TB incidence in urban areas and among out of school youth.

\section{Competing interests}

The authors declare that they have no competing interests.

\section{Authors' contributions}

JW: analyzed the data and wrote the paper, WS, MJ: managed the laboratory experiments, SV, AW, RC, WS, PM, and HMK: participated in critical review and manuscript writing, PM and HMK: conceived the idea. All authors participated in protocol development and read and approved the final version of the manuscript.

\section{Acknowledgements}

The authors thank the Uganda National TB and Leprosy Program, the various health institutions, the local Government authorities, Iganga/Mayuge Demographic Surveillance Site of the Makerere University School of Public Health for their collaboration. We thank John Baptist Bwanika and Kalungu Michael for helping in statistical data analysis. Our gratitude to the Infectious Diseases Institute (IDI) Makerere, the sponsor of the study, the participants for taking part in the study, all individuals living in the study area and the study staff.

\section{Funding}

This study was funded by the European and Developing Countries Clinical Trials Partnership (EDCTP) and one time support for purchasing laboratory reagents from Directorate General for Development Cooperation (DGDC) through the Flemish Interuniversity council (VLIR-UOS).

\section{Author details}

${ }^{1}$ Makerere University Iganga/Mayuge Demographic Surveillance Site, P.O BOX. 22418, Kampala, Uganda. ${ }^{2}$ KNCV Tuberculosis Foundation, The Hague, and CINIMA, Academic Medical Centre Amsterdam, Amsterdam, The Netherlands. ${ }^{3}$ Makerere University Infectious Diseases Institute, Kampala, Uganda. ${ }^{4}$ Department of Microbiology, Makerere University College of Health Sciences, Kampala, Uganda. ${ }^{5}$ Institute of Tropical Medicine, Antwerp, Belgium. ${ }^{6}$ University of Antwerp, Antwerp, Belgium. ${ }^{7}$ Department of Paediatrics and Child Health, Makerere University College of Health Sciences, Kampala, Uganda. ${ }^{8}$ Department of Medicine, Makerere University College of Health Sciences, Kampala, Uganda.

Received: 14 March 2013 Accepted: 24 July 2013

Published: 26 July 2013

\section{References}

1. World Health Organization: Global tuberculosis control. Geneva Switzerland: WHO Report 2011; 2011. whqlibdoc.who.int/publications/2011/ 9789241564380_eng.pdf.

2. Nemir RL: Perspectives in adolescent tuberculosis: three decades of experience. Pediatrics 1986, 78(3):399-405.

3. Kam A, Ford-Jones L, Malloy P, Khan K, Kitai I: Active tuberculosis among adolescents in Toronto, Canada: clinical features and delays in diagnosis. Pediatr Infect Dis J 2007, 26(4):355-356.

4. Trunz BB, Fine P, Dye C: Effect of BCG vaccination on childhood tuberculous meningitis and miliary tuberculosis worldwide: a metaanalysis and assessment of cost-effectiveness. Lancet 2006, 367(9517):1173-1180.

5. WHO: Department of vaccines and Biologicals. Issues relating to the use of $B C G$ in immunization programmes. WHON\&B/99.23. Geneva Switzerland; 1999. www.who.int/vaccines-documents/DocsPDF99/www9943.pdf. Accessed on Aug 2012.

6. Colditz GA, Berkey CS, Mosteller F, Brewer TF, Wilson ME, Burdick E, Fineberg HV: The efficacy of bacillus Calmette-Guerin vaccination of newborns and infants in the prevention of tuberculosis: meta-analyses of the published literature. Pediatrics 1995, 96(1 Pt 1):29-35.

7. Hatherill M: Prospects for elimination of childhood tuberculosis: the role of new vaccines. Arch Dis Child 2011, 96(9):851-856.

8. Mandalakas AM, Starke JR: Current concepts of childhood tuberculosis. Semin Pediatr Infect Dis 2005, 16(2):93-104.

9. Mahomed H, Hawkridge T, Verver S, Abrahams D, Geiter L, Hatherill M, Ehrlich R, Hanekom WA, Hussey GD: The tuberculin skin test versus QuantiFERON TB Gold $(\mathrm{R})$ in predicting tuberculosis disease in an adolescent cohort study in South Africa. PLoS One 2011, 6(3):17984.

10. World Health Organization: Global tuberculosis control. Geneva Switzerland; 2009. whqlibdoc.who.int/publications/2009/9789241563802_eng_doc.pdf. 
11. Strong BE, Kubica GP: Isolation and identification of Mycobacterium tuberculosis: a guide for the level II laboratory," Centers for Disease Control. HHS Publication No. (CDC); 1981:81-8390. http://books.google.co.ug/books? id $=$ VurMQEACAAJ.

12. Sekandi JN, Neuhauser D, Smyth K, Whalen CC: Active case finding of undetected tuberculosis among chronic coughers in a slum setting in Kampala, Uganda. Int J Tuberc Lung Dis 2009, 13(4):508-513.

13. Van't Hoog AH, Borgdorff MW, DeCock KM, Marston BJ, Muchiri BG, Odeny LO, Agaya JA, Meme HK, Githui WA, Laserson KF: High prevalence of pulmonary tuberculosis and inadequate case finding in rural western Kenya. Am J Respir Crit Care Med 2011, 183(9):1245-1253.

14. Corbett EL, Bandason T, Cheung YB, Munyati S, Godfrey-Faussett P, Hayes R, Churchyard G, Butterworth A, Mason P: Epidemiology of tuberculosis in a high HIV prevalence population provided with enhanced diagnosis of symptomatic disease. PLoS Med 2007, 4(1):e22.

15. Ayles H, Schaap A, Nota A, Sismanidis C, Tembwe R, De Haas P, Muyoyeta $M$, Beyers N: Prevalence of tuberculosis, HIV and respiratory symptoms in two Zambian communities: implications for tuberculosis control in the era of HIV. PLoS One 2009, 4(5):e5602.

16. Middelkoop K, Bekker LG, Myer L, Whitelaw A, Grant A, Kaplan G, Mclntyre J, Wood R: Antiretroviral program associated with reduction in untreated prevalent tuberculosis in a South African township. Am J Respir Crit Care Med, 182(8):1080-1085

17. Corbett EL, Bandason T, Cheung YB, Makamure B, Dauya E, Munyati SS, Churchyard GJ, Williams BG, Butterworth AE, Mungofa S, et al: Prevalent infectious tuberculosis in Harare, Zimbabwe: burden, risk factors and implications for control. Int J Tuberc Lung Dis 2009, 13(10):1231-1237.

18. Hoa NB, Sy DN, Nhung NV, Tiemersma EW, Borgdorff MW, Cobelens FG: National survey of tuberculosis prevalence in Viet Nam. Bull World Health Organ 2010, 88(4):273-280. http://www.who.int/bulletin/volumes/88/4/09-067801/en/.

19. Murhekar MV, Kolappan C, Gopi PG, Chakraborty AK, Sehgal SC: Tuberculosis situation among tribal population of Car Nicobar, India, 15 years after intensive tuberculosis control project and implementation of a national tuberculosis programme. Bull World Health Organ 2004, 82(11):836-843.

20. Tupasi TE, Radhakrishna S, Rivera AB, Pascual ML, Quelapio MI, Co VM, Villa ML, Beltran G, Legaspi JD, Mangubat NV, et al: The 1997 Nationwide Tuberculosis Prevalence Survey in the Philippines. Int I Tuberc Lung Dis 1999, 3(6):471-477.

21. China Tuberculosis Control Collaboration: The effect of tuberculosis control in China. Lancet 2004, 364:417-422.

22. Gopi PGSR, Radhakrishna S, Kolappan C, Sadacharam K, Devi TS, Frieden TR, Narayanan PR: A baseline survey of the prevalence of tuberculosis in a community in south India at the commencement of a DOTS programme. Int J Tuberc Lung Dis 2003, 7(12):1154-1162.

23. Hong YP, Kim SJ, Lew WJ, Lee EK, Han YC: The seventh nationwide tuberculosis prevalence survey in Korea, 1995. Int J Tuberc Lung Dis 1998, 2(1):27-36.

24. Datta M, Radhamani MP, Sadacharam K, Selvaraj R, Rao DL, Rao RS, Gopalan BN, Prabhakar R: Survey for tuberculosis in a tribal population in North Arcot District. Int J Tuberc Lung Dis 2001, 5(3):240-249.

\section{Submit your next manuscript to BioMed Central and take full advantage of:}

- Convenient online submission

- Thorough peer review

- No space constraints or color figure charges

- Immediate publication on acceptance

- Inclusion in PubMed, CAS, Scopus and Google Scholar

- Research which is freely available for redistribution 